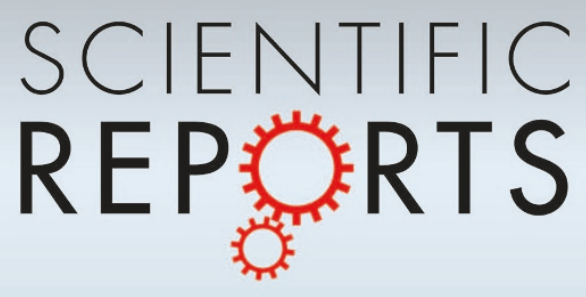

OPEN

SUBJECT AREAS:

ATMOSPHERIC SCIENCE

ENVIRONMENTAL SCIENCES

Received

2 June 2014

Accepted

3 November 2014

Published

1 December 2014

Correspondence and requests for materials should be addressed to

N.H. (huangn@lzu. edu.cn)

\title{
Analysis of Wind-blown Sand Movement over Transverse Dunes
}

\author{
Hong Jiang ${ }^{1,2}$, Ning Huang ${ }^{1} \&$ Yuanjian Zhu ${ }^{3}$
}

\begin{abstract}
'Key Laboratory of Mechanics on Disaster and Environment in Western China, Lanzhou University, Lanzhou 730000, China,
${ }^{2}$ Laboratoire de Mécanique des Fluides et d'Acoustique, Ecole Centrale de Lyon, Ecully 69130, France, ${ }^{3}$ Research and Development Center, Aviation Industry Corporation of China Shaanxi Aircraft Industry (Group) Corporation Limited, Hanzhong 723009, China.
\end{abstract}

\begin{abstract}
Wind-blown sand movement often occurs in a very complicated desert environment where sand dunes and ripples are the basic forms. However, most current studies on the theoretic and numerical models of wind-blown sand movement only consider ideal conditions such as steady wind velocity, flat sand surface, etc. In fact, the windward slope gradient plays a great role in the lift-off and sand particle saltation. In this paper, we propose a numerical model for the coupling effect between wind flow and saltating sand particles to simulate wind-blown sand movement over the slope surface and use the SIMPLE algorithm to calculate wind flow and simulate sands transport by tracking sand particle trajectories. We furthermore compare the result of numerical simulation with wind tunnel experiments. These results prove that sand particles have obvious effect on wind flow, especially that over the leeward slope. This study is a preliminary study on windblown sand movement in a complex terrain, and is of significance in the control of dust storms and land desertification.
\end{abstract}

$\mathrm{n}$ recent years, sandstorms and land desertification induced by wind-blown sand movement have become one of the most important environmental issues. Investigating the mechanisms of wind-sand movement can provide solutions to control and prevent wind-sand hazards. Except for wind events over fine textured soils in which suspension is dominant, saltation is the predominant sand transport mode. For this reason, many numerical simulations for saltation have been carried out after the Symposium of International Windblown Sand Physics Academy in $1985^{1-5}$. To resolve discrepancies between classical saltation theory and field measurements, different numerical models were established for study state saltation ${ }^{6-8}$. Since this century, the effect of turbulence has drawn more and more attentions ${ }^{7,8}$. Sand saltation was simulated with the coupled model, where the airflow was computed by the k- $\varepsilon$ turbulence model ${ }^{8}$. The particle motion was simulated on the sand bed and a jump was first observed in the saturated flux 9 . It was found that the intensity and the Lagrangian time scale of turbulence in the saltation layer had obvious effects on saltation transport ${ }^{6,10,11}$. Nevertheless, the bed surfaces were flat in above simulation models and the morphology effect was not taken into consideration.

Recently the intricate interactions among dune morphology, wind flow and sand transport have drawn increasing attention. Field and wind tunnel experiments were carried out on flow dynamics over the windward slope and the sediment dynamics on the lee-side. The measured wind velocity profiles were not log-linear over the windward slope ${ }^{12,13}$. Through these wind tunnel experiments and field observations ${ }^{14-16}$, it revealed that shear stress increased progressively along the windward slope and the wind velocity close to the surface reaches its maximum upwind of the crest $^{14-16}$. By measuring the flow velocity over the leeward slope, it showed that above the separation cell there were a mixing layer and a highly turbulent shear zone, implying that flow reattachment and subsequent sediment transport occurred on the leeward slope ${ }^{17}$. However, turbulence and return flows couldn't be accurately quantified in the wind tunnel because of the instrument's limitations ${ }^{18}$. Limitations originated from the wind and sand flow complexity and desert morphology conditions in the natural dune environments ${ }^{19-21}$.

Many researchers have conducted computational fluid dynamics (CFD) simulations to solve the Navier-Stokes equations for turbulent wind over barchans and transverse dunes ${ }^{19,22-28}$. Some focused on the lee side flow over dunes $^{20,22,24,26,27}$. The downwind reattachment and return flow zones in the lee side of a transverse dune were quantitatively described ${ }^{24}$ and it was found that the length of recirculation region after the dune brink depended strongly on the shape of dune. The wind profile and separation streamline over barchans and transverse dunes were firstly simulated by Herrmannn et al. ${ }^{28}$.

In addition, Araújo et al. ${ }^{26}$ simulated the average turbulent wind flow over a transverse dune by means of computational fluid dynamics simulations and their results showed that there is a dependence of the separation 


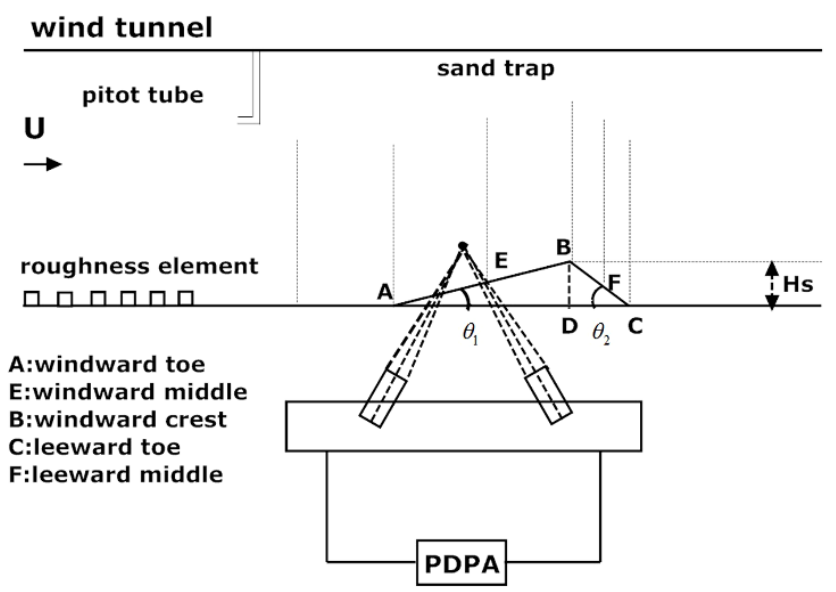

Figure $1 \mid$ Experiment apparatus in wind tunnel.

streamline length on the wind shear velocity ${ }^{26}$. In above simulations, the saltation transport of sand and its effects on wind flow were ignored.

In the present study, a two-way coupling wind-blown sand model on the interactions among turbulence flow, morphology and saltation was proposed to simulate the windblown sand movement over a transverse dune. The conservation equations of the wind flow field were calculated and discretized by using the finite volume method. The semi-implicit method for pressure-linked equations (SIMPLE) algorithm for the pressure-velocity coupling was used to iteratively calculate the pressure and velocity fields until mass and momentum continuity errors were adequately small ${ }^{29}$. Sand transport was simulated by tracking the movement of every single particle over the slope landform. Wind flows over the windward and the leeward slopes were investigated under the influence of aeolian sand particles. At last, simulation results were discussed in detail.

\section{Results}

Figure 1 shows the schematic of the experimental arrangement. The roughness elements were set at the inlet of the wind tunnel in order to simulate atmospheric boundary layer. The triangular slope was located at $7.3 \mathrm{~m}$ away from the roughness element zone, $\theta_{1}$ was the angle of the windward slope and $\theta_{2}$ was the angle the leeward slope. Hs was the height of the transverse dune. The vertical sand traps were set at different positions over the $0.1 \mathrm{~m}$ high slope and used to measure the mass flux. Both wind tunnel experiment parameters and numerical simulation triangular slope parameters are listed in Table 1 . Sand particles with diameter of $250 \mu \mathrm{m}$ and density of $2650 \mathrm{~kg} / \mathrm{m}^{3}$ were uniformly distributed over the bed surface and the slope surface. The passive vertical array of sand traps with $20 \mathrm{~mm}$ $\times 20 \mathrm{~mm}$ collector inlets were positioned at different positions over the slope to measure the mass flux profile. Although the presence of sand traps disturbed the velocity field and sequentially affected the sampling efficiency of sand traps, they were widely used due to their simple structure and low cost. The sampling efficiency of sand traps was relatively low and varied greatly in the zone near the bed. However, in the zone far away from the bed, the efficiency gradually became better ${ }^{30,31}$.

Table 1 | Wind tunnel experiment and numerical simulation parameters

\begin{tabular}{llll} 
case & $\mathrm{Hs}(\mathrm{m})$ & $\theta_{1}$ & $\theta_{2}$ \\
\hline PDPA & 0.05 & $17.35^{\circ}$ & $27.5^{\circ}$ \\
Sand trap & 0.1 & $17.35^{\circ}$ & $27.5^{\circ}$ \\
Simulation model & 0.1 & $10^{\circ}$ & $30^{\circ}$ \\
\hline
\end{tabular}

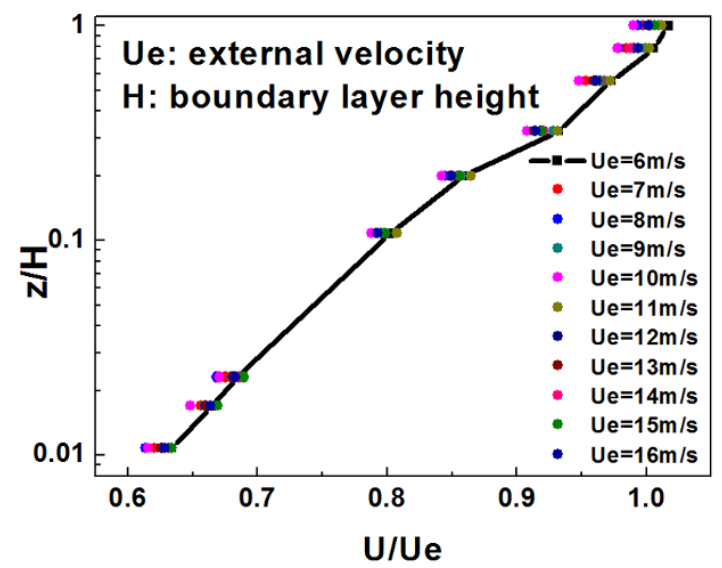

Figure $2 \mid$ Wind velocity profiles at initial state in wind tunnel.

Figure 2 shows different steady wind velocities in the wind tunnel over the flat bed at the position where the wind flow can fully develop. In the Figure 2, the height is presented by log scale. The fitted wind velocity profile was used as the initial wind speed at the inlet in the simulation model, with a view to obtain a result consistent with the actual condition.

Figure 3 shows the mass flux profiles before the windward slope bottom at friction velocity of $0.5 \mathrm{~m} / \mathrm{s}$ in the wind tunnel. The vertical sand traps were set to measure aeolian sands at the positions of $2.35 \mathrm{Hs}$ and $5.2 \mathrm{Hs}$ from the windward slope bottom and $7.065 \mathrm{~m}$ and $6.78 \mathrm{~m}$ away from the roughness element zone where the wind was steady. Hs is the height of the slope $(0.1 \mathrm{~m})$. The mass flux profiles were fitted into the following function with respect to the height $\mathrm{z}$ :

$$
Q(z)=0.00149+1.25134 e^{(-z / 0.03148)}
$$

In the numerical simulation, this function is adopted as the initial sand particle distribution at the entrance.

The movement equations of saltating particles subject to gravity and aerodynamic drag are expressed as follows:

$$
\begin{gathered}
m_{P} \frac{d^{2} x}{d t^{2}}=F_{D x}=\frac{C_{D}\left(R_{e}\right) \pi D^{2} \rho_{a}}{8}\left(u-\frac{d x}{d t}\right) V_{r} \\
m_{P} \frac{d^{2} z}{d t^{2}}=F_{D z}-m_{p} g=\frac{C_{D}\left(R_{e}\right) \pi D^{2} \rho_{a}}{8}\left(w-\frac{d z}{d t}\right) V_{r}-\frac{\rho_{p} \pi D^{3}}{6} g
\end{gathered}
$$

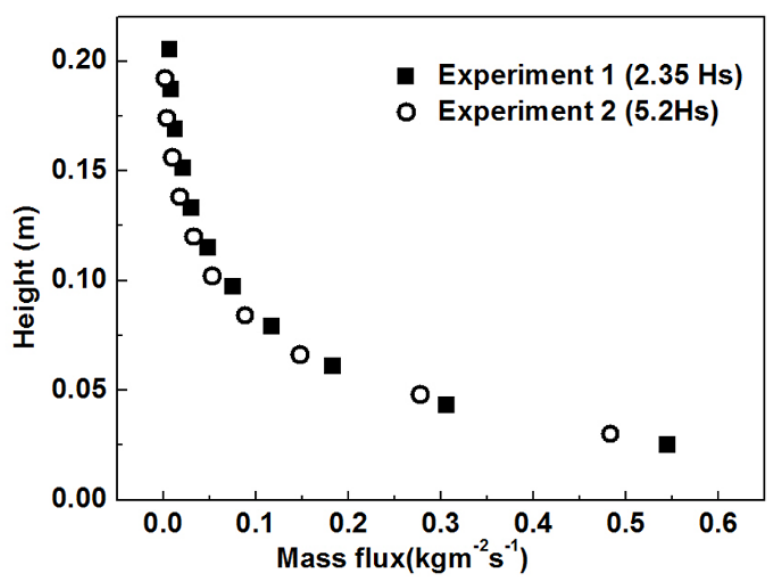

Figure 3 Mass flux profiles in wind tunnel experiments before windward slope toe. 
Where, $\mathrm{m}_{\mathrm{p}}$ denotes the particle mass; $\mathrm{x}$ and $\mathrm{z}$ the particle positions in the Cartesian coordinates, respectively, $\mathrm{x}$ is the distance away from entrance, and $\mathrm{z}$ is the height of the particle away from the bed surface; $\mathrm{g}$ is the acceleration due to gravity; $\mathrm{D}$ denotes the average particle diameter; $\rho_{\mathrm{p}}=2650 \mathrm{~kg} / \mathrm{m}^{3}$ is the density of sand, $\rho_{\mathrm{a}}=1.22 \mathrm{~kg} / \mathrm{m}^{3}$ is the density of air, $\rho_{\mathrm{a}}=1.22 \mathrm{~kg} / \mathrm{m}^{3}$ is the density of air $\mathrm{u}$ and $\mathrm{w}$ are the wind velocities in the $\mathrm{x}$ - and $\mathrm{z}$-axis, respectively. In Equation (2) and (3), $V_{r}, R_{e}$ and $C_{D}\left(R_{e}\right)$ denote the relative speed, the Reynolds number of the sand movement, and the wind flow drag coefficient, respectively and are given as:

$$
\begin{gathered}
V_{r}=\sqrt{\left(\frac{d x}{d t}-u\right)^{2}+\left(\frac{d z}{d t}-w\right)^{2}} \\
R_{e}=\frac{\rho_{p} D}{\mu} V_{r} \\
C_{D}\left(R_{e}\right)=\left\{\begin{array}{l}
\text { if }\left(R_{e}=0\right), C_{D}\left(R_{e}\right)=0 . \\
\text { if }\left(0<R_{e}<1\right), C_{D}\left(R_{e}\right)=24 / R_{e} \\
\text { if }\left(1<R_{e}<400\right), C_{D}\left(R_{e}\right)=\left(24 / R_{e}\right) * 0.646 \\
\text { if }\left(400<R_{e}<3 \times 10^{5}\right), C_{D}\left(R_{e}\right)=0.5 \\
\text { if }\left(3 \times 10^{5}<R_{e}<2 \times 10^{6}\right), C_{D}\left(R_{e}\right)=3.66 * 10^{-4} * R_{e} 0.4275 \\
\text { if }\left(R_{e}>2 \times 10^{6}\right), C_{D}\left(R_{e}\right)=0.18
\end{array}\right.
\end{gathered}
$$

The initial conditions of Equation (2) and (3) are

$$
t=0, x=0, \frac{d x_{n}}{d t}=f(z(n), u(z)), \frac{d z}{d t}=0
$$

where, $z(n)$ is the height of the $n$-th particle; $f(z(n), u(z))$ is a function as the particle's height and the velocity, $\mathrm{u}(\mathrm{z})$, which is corresponding to the wind profile and particle position. The particle's initial velocity distribution at the inlet boundary is related to the wind profile obtained in the wind tunnel experiment and shown in Figure 2. The particle's initial distribution at the inlet boundary is the mass flux profile obtained in the wind tunnel experiment, as shown in Figure 3 and given in Equation (1). The particle's velocity is related to the wind velocity at the inlet boundary.

The wind flow field is governed by the mass conservation equation and the momentum conservation equation:

$$
\begin{gathered}
\frac{\partial u}{\partial x}+\frac{\partial w}{\partial z}=0 \\
\rho_{a}\left(\frac{\partial u}{\partial t}+\frac{\partial u u}{\partial x}+\frac{\partial u w}{\partial z}\right)=\frac{\partial}{\partial x}\left(\mu \frac{\partial u}{\partial x}\right)+\frac{\partial}{\partial z}\left(\mu \frac{\partial u}{\partial z}\right)-\frac{\partial p}{\partial x}+S_{x} \\
\rho_{a}\left(\frac{\partial w}{\partial t}+\frac{\partial w u}{\partial x}+\frac{\partial w w}{\partial z}\right)=\frac{\partial}{\partial x}\left(\mu \frac{\partial w}{\partial x}\right)+\frac{\partial}{\partial z}\left(\mu \frac{\partial w}{\partial z}\right)-\frac{\partial p}{\partial z}+S_{z}(10)
\end{gathered}
$$

with their initial conditions being

$$
\mathrm{t}=0: \mathrm{u}(0, z)=\left(u_{*} / k\right) \ln \left(z / z_{0}\right), u(x, z)=0, w(x, z)=0
$$

Where $\mathrm{k}$ is von-Kármán constant, $\mathrm{z}_{0}$ was the sand bed roughness and $u_{*}$ was the friction velocity. We discussed the wind field for $u_{*}=0.5$ and $z_{0}=D / 30$, where $\mathrm{D}$ was the sand particle diameter. And their boundary conditions being

$$
\begin{gathered}
x=x_{\text {out }}: \frac{\partial u\left(x_{\text {out }}, z\right)}{\partial x}=0, w=0 \\
\mathrm{z}=z_{\max }: \frac{\partial u\left(x, z_{\max }\right)}{\partial z}=u_{* 0}, \frac{\partial w\left(x, z_{\max }\right)}{\partial z}=0 \\
\mathrm{z} \leq \mathrm{z}_{\text {triangle }}(x): u(x, z)=0, w(x, z)=0
\end{gathered}
$$

The additional drag force resulting from the presence of sand particles and applied on the wind flow is

$$
\begin{gathered}
S_{x}=-\Sigma_{p=1}^{p=n} F_{D \mathrm{x}} \\
S_{z}=-\Sigma_{p=1}^{p=n} F_{D \mathrm{z}} \\
F_{D x}=\frac{C_{D}\left(R_{e}\right) \pi D^{2} \rho_{a}}{8}\left(u-\frac{d x}{d t}\right) \sqrt{\left(u-\frac{d x}{d t}\right)^{2}+\left(w-\frac{d z}{d t}\right)^{2}} \\
F_{D z}=\frac{C_{D}\left(R_{e}\right) \pi D^{2} \rho_{a}}{8}\left(w-\frac{d z}{d t}\right) \sqrt{\left(u-\frac{d x}{d t}\right)^{2}+\left(w-\frac{d z}{d t}\right)^{2}}
\end{gathered}
$$

Where $\mathrm{x}$ is the distance away from the inlet and $\mathrm{z}$ is the height of particle away from the surface. The additional drag force components resulting from the presence of sand particles $F_{x}(i, j)$ and $F_{z}(i, j)$ applied on the wind flow in the $\mathrm{x}$ - and $\mathrm{z}$ - directions are included in $\mathrm{S}_{\mathrm{x}}$ and $S_{z}$ (generalized source terms) that reflect the coupling of sand and wind flow fields.

Wind field boundary conditions are 1) at the ground surface, the no-slip boundary condition is used; 2) at the domain top, the derivatives of variables $\mathrm{u}, \mathrm{w}, \mathrm{p}$ with respect to the vertical variable $\mathrm{z}$ are set equal to zero; 3 ) at the inlet boundary, the initial value of the wind velocity profile is determined by fitting the velocity in the wind tunnel experiment; 4 ) at the outlet boundary, the normal derivatives of variables $\mathrm{u}, \mathrm{w}, \mathrm{p}$ with respect to $\mathrm{x}$ are set equal to zero. The outlet boundary is far away from the negative pressure zone where the wind flow can fully develop.

In the wind-blown sand flow field, sand particles which lift off from the bed surface into the saltation layer eventually drop back the surface due to gravity. When they affect downward other particles on the sand bed, they may or may not rebound themselves or eject other particles from on the bed. This stochastic process is affected by the sand-bed characteristics such as the grain size, velocity and angle of the impacting particles as well as the bed property. The investigations on how the velocity and angle of impacting particles were affected by turbulent flow in a random way in the impact process were conducted in the wind tunnel and numerical simulations ${ }^{24,32}$. The natural sand particles are random in size and shape. As they move on the surface, their distribution as well as impacting positions and incident angles, etc, all are very complicated. Other random impact parameters such as the recovery coefficient are often used in many sand-bed impact models. Although a lot of sand-bed impact experiments and numerical simulations have been carried on, this random property cannot be described accurately. The collision process of beads had been measured in experiments in order to obtain the splash function ${ }^{33}$. Besides, experiment results can be better repeated by phasing numerical simulation in terms of dimensionless variables $^{34}$. However, the coefficients of restitution and friction may be different for the spheres they used and sands. It was found out that the slope surface could affect the grains ejection and the ratio of the ejection speed to the impact speed decreased with the slope, while the ejected angle and the number of ejected grains increased with the slope $^{32}$. In this paper, the splash function determined experimentally $^{35,36}$ is adopted to simulate the sand-bed impact process and given as follows. The statistical laws of splash function used by Vinkovic et al. ${ }^{36}$ derive from the models proposed by Anderson et al. ${ }^{2}$. However, the splash function splash function used by Vinkovic et al. ${ }^{36}$ could calculate the velocity and number of rebound sand and eject sand. For the splash function of Anderson et al. ${ }^{2}$, the rebound and eject velocity couldn't be calculated. The splash functions only based on the velocity of the impacting grain, and it is independent of the diameter of the impacting sand particle. Some coefficients were adapted from the experimental observations $^{36}$. Some coefficients were adapted from the experimental observations ${ }^{36}$. 


$$
\begin{gathered}
\left|V_{r e}\right|=0.3\left|V_{i m}\right| \pm 0.25\left|V_{i m}\right| \\
\alpha_{r e}=30^{0} \pm 15^{0} \\
\left|V_{e j}\right|=0.3\left|V_{i m}\right| \pm 0.5\left|V_{e j}\right| \\
\alpha_{e j}=55^{0} \pm 5^{0} \\
N_{p}=\max \left[0,3.36 \sin \left(\alpha_{i m}\right)\left(5.72 V_{i m}-0.915\right)\right]
\end{gathered}
$$

where $V_{r e}$ and $\alpha_{r e}$ are the rebounding velocity and angle of sand particles, respectively, $V_{i m}$ and $\alpha_{i m}$ are the impact velocity and angle, respectively, $V_{e j}$ and $\alpha_{e j}$ are the ejection velocity and angle, respectively; $N_{p}$ is the number of splashed particles.

Figure 4 shows both the simulated results and experimental results in wind tunnel for horizontal wind velocity profiles over transverse dune, where Ue is external velocity. Figure 4 reveals the wind profile were no longer linear logarithmic distribution over the windward slope while it is linear logarithmic distribution over flat surface. From Figure 4, wind velocity gradient with height increase at the windward slope toe of transverse dune. However, wind velocity gradient with height increase firstly and then decrease at the leeward slope toe of transverse dune. The wind profiles present different distribution over windward slope and leeward slope. In addition, it could be seen that the simulated wind profiles distribution is consistent with the observed results in wind tunnel at windward toe, middle position of windward slope as well as leeward toe. The position of windward middle means it is the middle of the windward slope toe and wind- ward crest. As shown in Figure 1, windward toe, windward middle and windward crest is respectively $\mathrm{A}, \mathrm{E}$ and $\mathrm{B}$. It demonstrated that the simulation model of wind field over transverse dune was verifiable and effective. At the position of leeward toe, the wind velocity is negative below $2 / 3 \mathrm{Hs}$ and positive above $2 / 3 \mathrm{Hs}$ that reveals the leeward slope toe is in the region of reverse flow. It is found that the length of the zone of reverse flow at the dune lee displays a surprisingly strong dependence on the wind shear velocity ${ }^{26}$. It is the first time quantifying the profile of lee flow, which displays a change in flow direction as the height increases since Araújo et $\mathrm{al}^{26}$ for the first time investigated quantitatively the reversing average turbulent flow shear velocity at the surface in the dune lee ${ }^{26}$. Figure 4 shows the absolute error of U/Ue in wind tunnel experiment and simulation model at different positions (windward toe, windward middle, leeward toe). The absolute errors of U/Ue are less than 0.05 in most area of the wind field. However, there are respectively large errors of $\mathrm{U} / \mathrm{Ue}$ above the reverse region $(0.25 \mathrm{H}$ to $0.5 \mathrm{H})$ at the position of leeward toe. The wind profiles simulated according to our model show the same distribution over the dune as what obtained in the experiments.

Figure 5 and Figure 6 present the horizontal and vertical wind field velocity over transverse dune observed by PDPA for $\mathrm{u} *=0.5 \mathrm{~m} / \mathrm{s}$ where Hs is $0.05 \mathrm{~m}$. Figure 7 and Figure 8 present the simulated the horizontal and vertical wind velocity profiles of $\mathrm{u}_{*}=0.5 \mathrm{~m} / \mathrm{s}$ for a pure wind field. The wind flow field over the transverse dune has higher velocities and complex flow structure. It can be seen that the horizontal wind accelerated over the windward slope. There is a reversed flow region in lee side. Both the numerical simulation results and experimental measurement results show uniformly varying
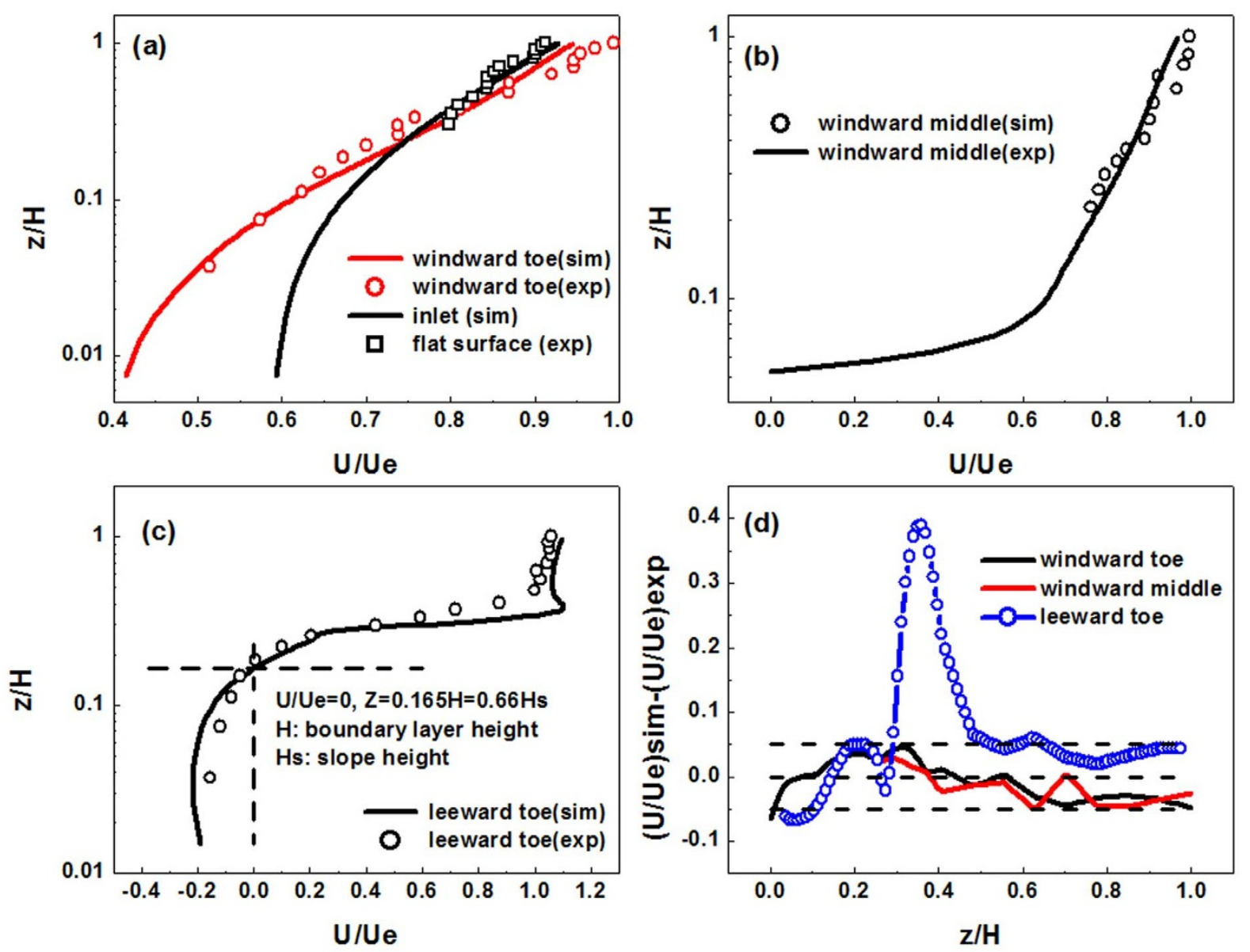

Figure 4 | Comparison of horizontal wind velocity profiles over transverse dune. 


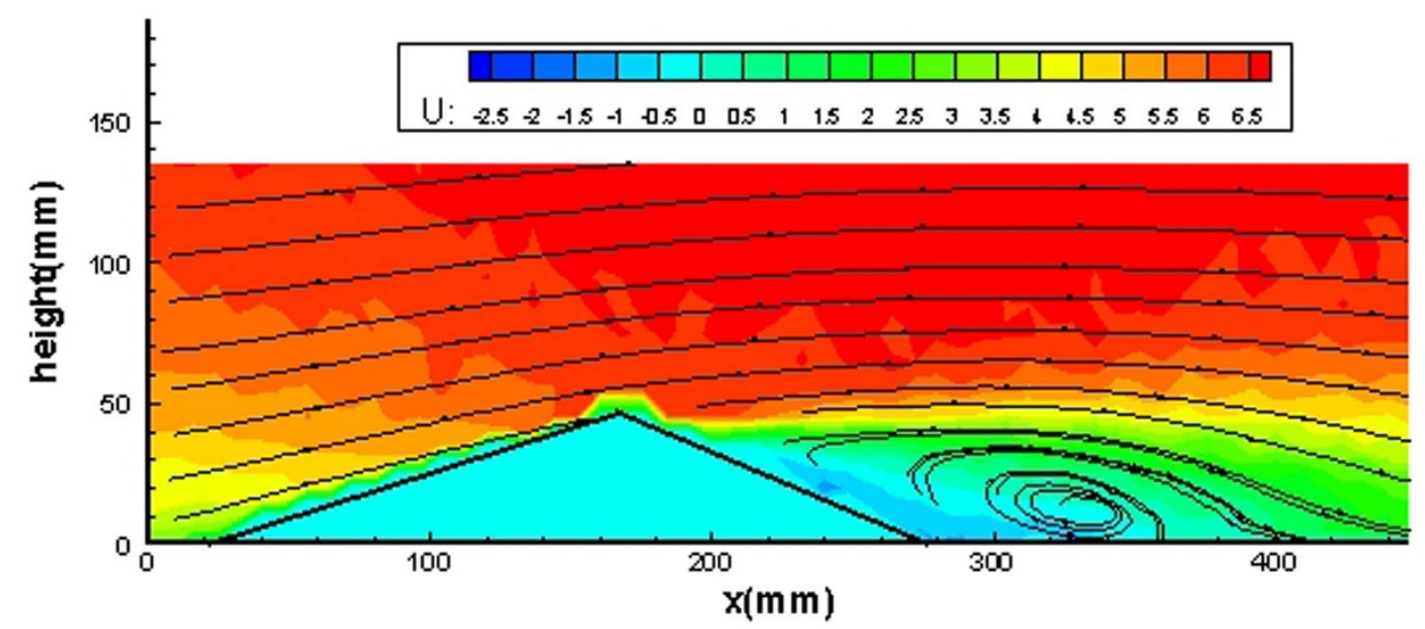

Figure 5 | Horizontal wind velocity field observed by PDPA in wind tunnel.

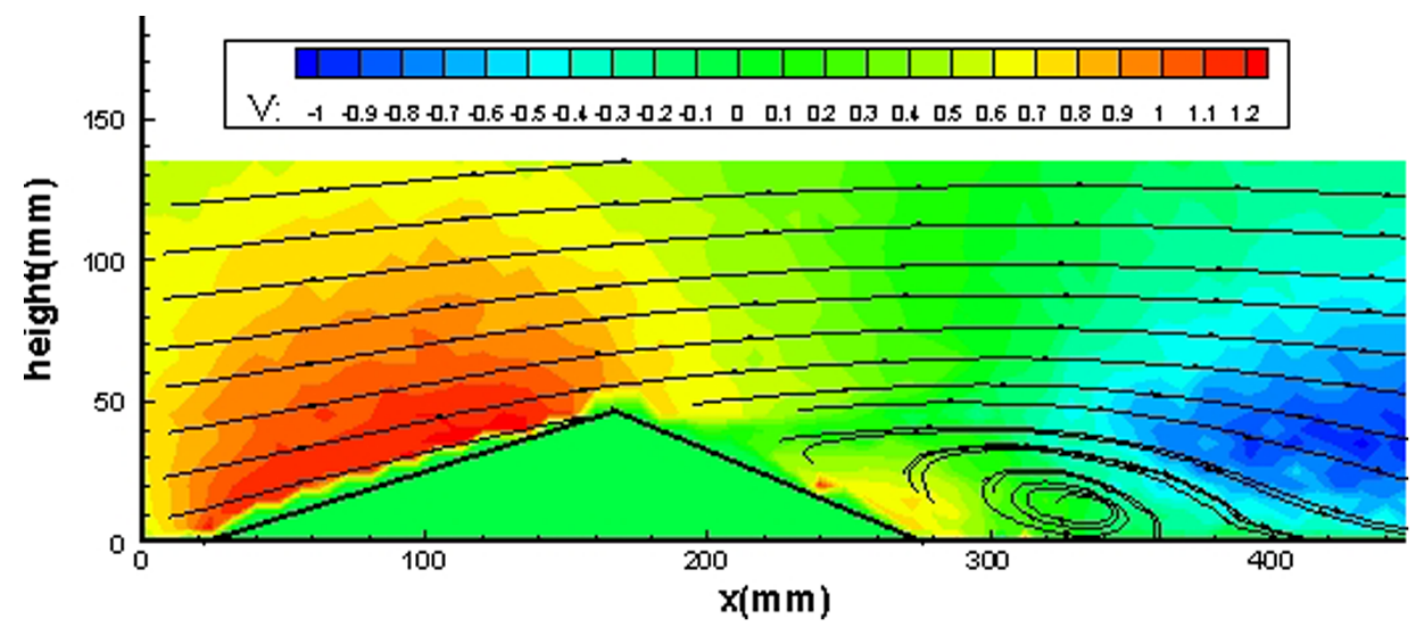

Figure 6 | Vertical wind velocity field observed by PDPA in wind tunnel.

patterns in regard to the wind velocity profiles at discrete positions over the dune.

Figure 9 and Figure 10 present simulated wind velocities in windblown sand field coupling the wind flow field with sand flow field in the model. The wind-sand coupling effect can greatly change the wind flow field over transverse dune. The observation of the flow streamline reveals that the reversed flow region over the leeward slope become larger in the coupled field than that in the uncoupled field.

Figure 11 reveals that the mass flux of sand particles gradually decreases with height over the windward slope and increases as they horizontally approach the windward slope top where $\mathrm{Hs}$ is $0.1 \mathrm{~m}$.

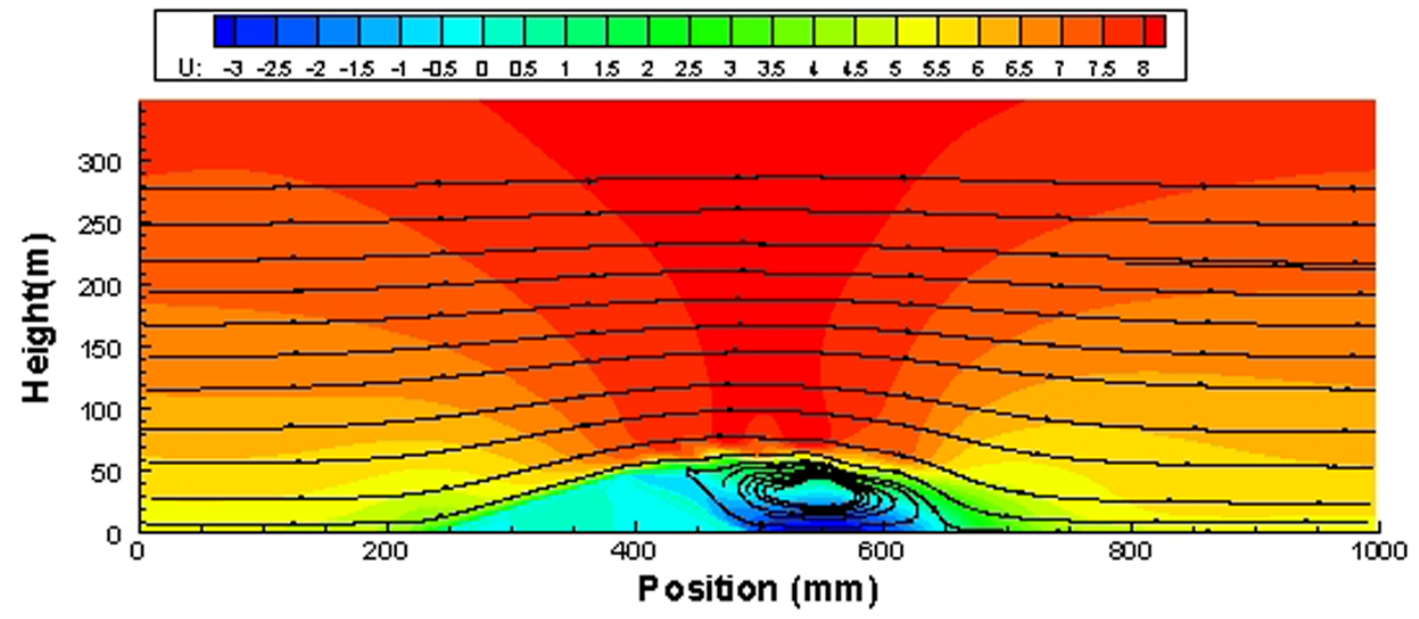

Figure $7 \mid$ Simulated pure horizontal wind field. 


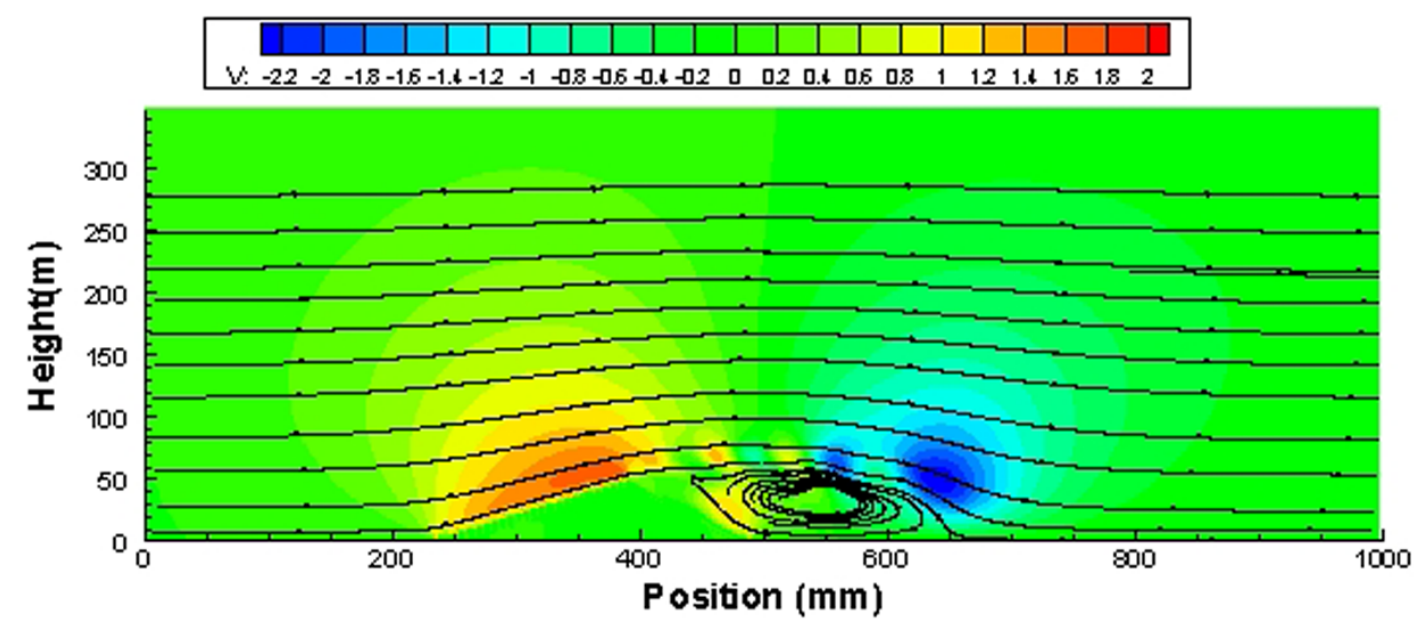

Figure 8 | Simulated pure vertical wind field.

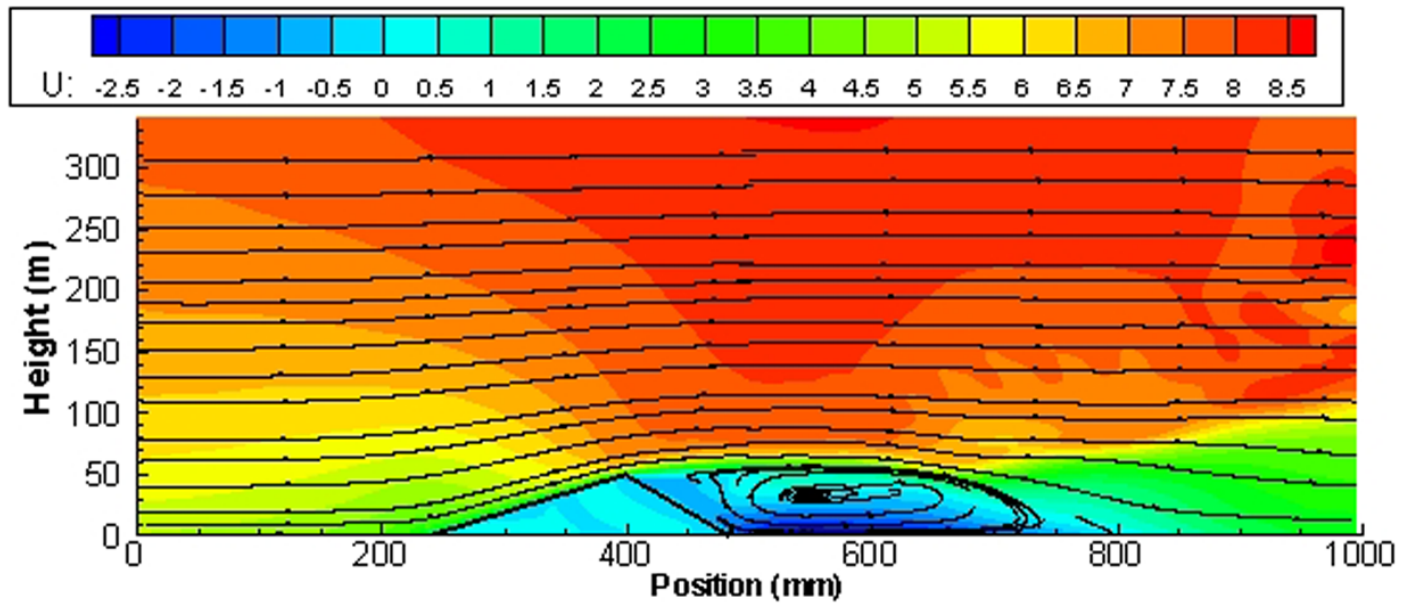

Figure 9 | Simulated horizontal wind velocities in wind-blown sand field.

The numerical simulations results show a good agreement with experimental measurement results (Hs is $0.1 \mathrm{~m}$ ).

\section{Discussion}

From Figure 5 shows the re-attachment distance was $5 \mathrm{Hs}$ in the wind tunnel (from $170 \mathrm{~mm}$ to $420 \mathrm{~mm}$ ) which is the horizontal distance from transverse dune crest to the end of the reverse flow zone. Through analyzing Figure 7, it reveals re-attachment distance is mostly $5 \mathrm{Hs}$ in the simulation model (from $400 \mathrm{~mm}$ to $650 \mathrm{~mm}$ ). Figure 7 and Figure 8 present a positive vertical velocity acceleration region existed over the windward slope due to the lift force of windward slope. A negative vertical velocity acceleration region is located next to the edge of reverse region. The positive acceleration region

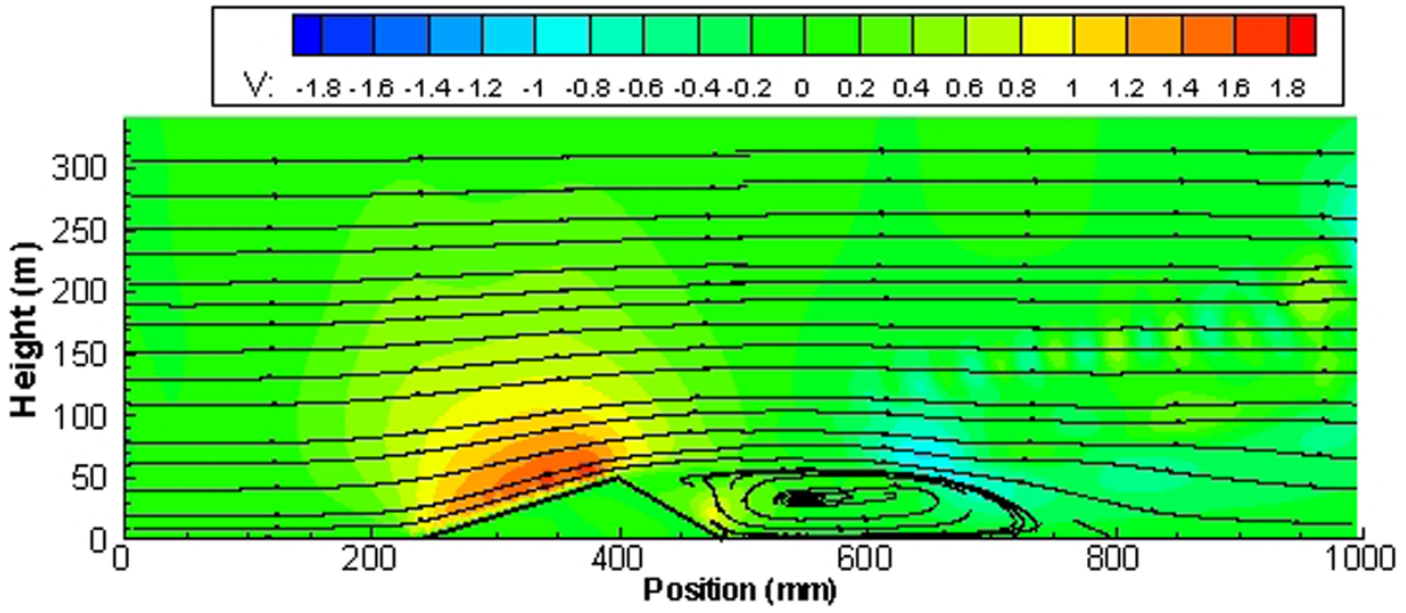

Figure 10 Simulated vertical wind velocities in wind-blown sand field. 

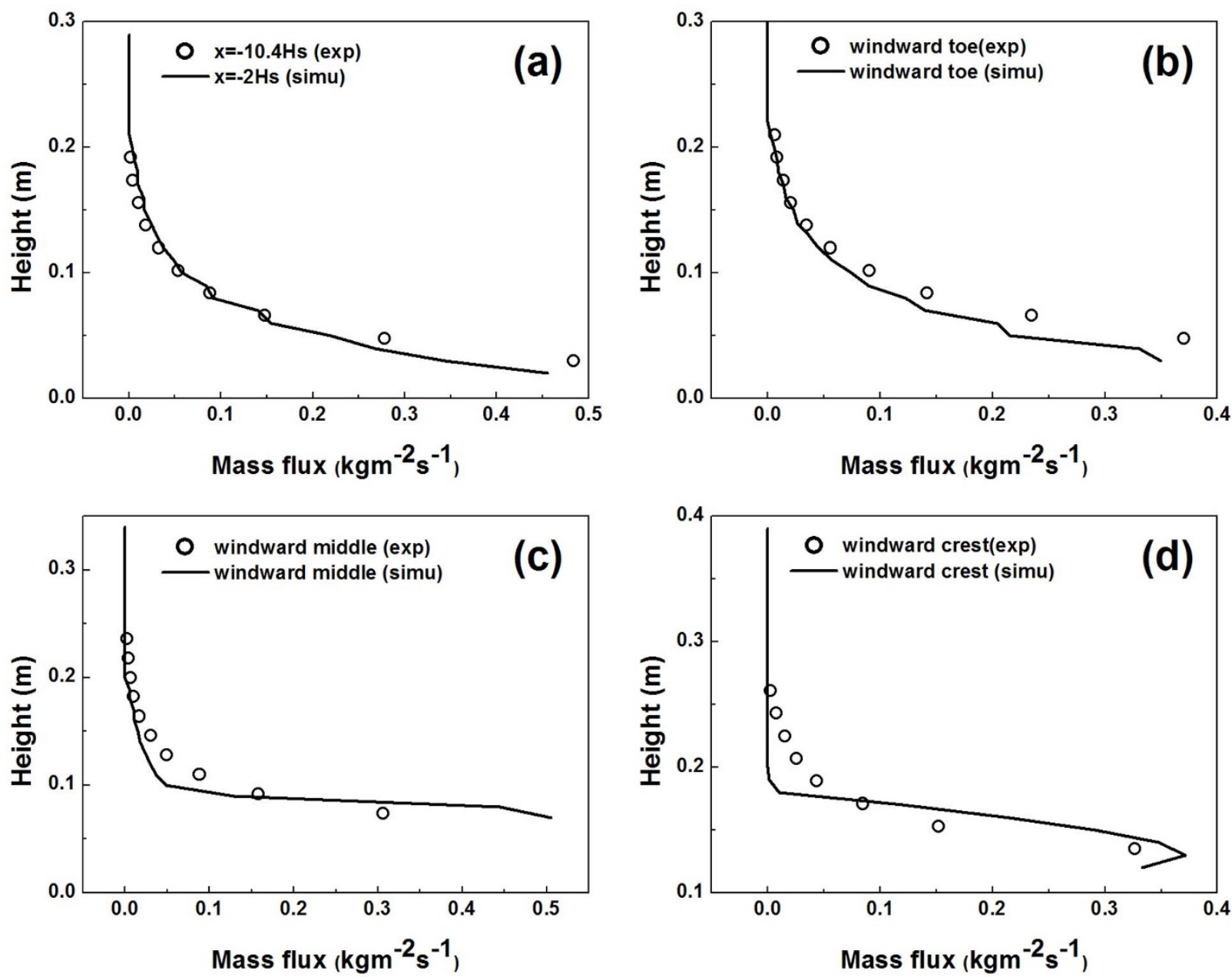

Figure $11 \mid$ Observed and simulated mass flux profiles over transverse dune.

had the symmetry axis which is perpendicular with the windward slope surface at the windward slope middle.

In addition, the re-attachment distance was $5 \mathrm{Hs}$ in pure wind field whereas the re-attachment distance was $9 \mathrm{Hs}$ (from $400 \mathrm{~mm}$ to $850 \mathrm{~mm}$ ) in the coupled model, which is accordant with the simulated results that the re-attachment distance is $4-8$ times the downwind dune height in average obtained ${ }^{17,37}$. These simulated results $s^{17,37}$ also agree with the field observation results of Parteli et al. ${ }^{38}$, they measured the length of the flow reattachment region for the transverse dune of different profiles and sizes and found a similar result ${ }^{38}$.
In case of broad hills, re-attachment distance was found to be 5-10 times of the hill height ${ }^{39}$. It can be seen that the wind-sand coupling plays a significant role in the increase in the re-attachment distance. The lee-side secondary flow pattern and the re-attachment are related not only to the bed forms downwind of the dune but also to the wind-sand coupling effect. The wind-sand coupling effect affects the dune geometry and atmospheric stability ${ }^{37}$.

Compared with Figure 8, in the lee side the negative vertical velocity acceleration region became smaller which was located next to the extended reverse region. The wind field structure was changed with

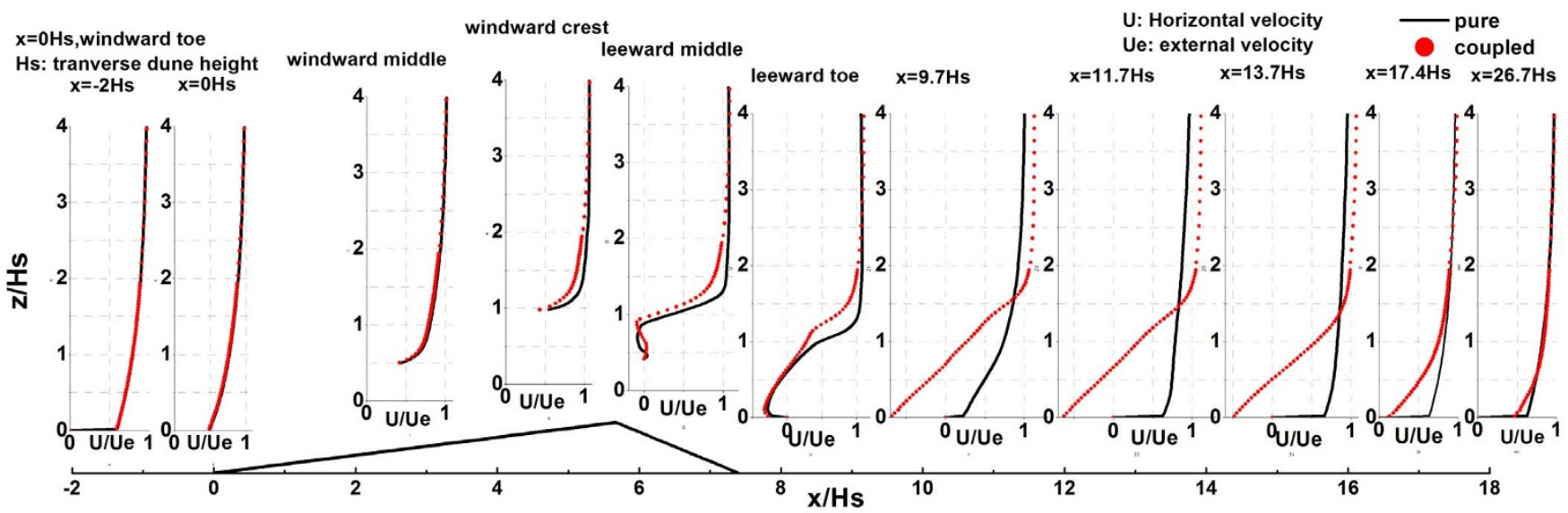

Figure $12 \mid$ Horizontal velocity profiles over transverse dune. 


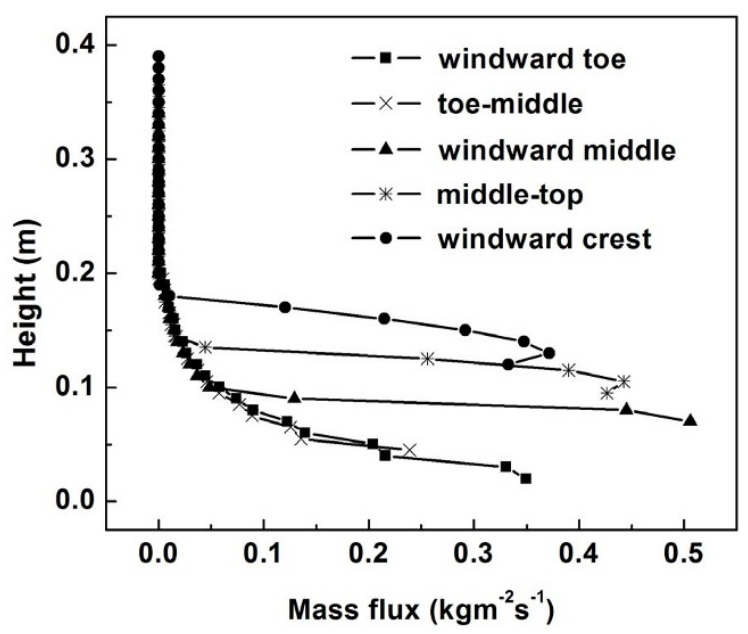

Figure 13 Simulated mass flux profiles over windward of transverse dune.

more and more sand particles take off, impact on the sand bed and then maybe eject or splash other sand particles. The weakened negative vertical velocity increases sand particles saltation length, thus extends reverse region.

Figure 12 shows that the horizontal velocity distribution of wind over transverse dune in pure wind field and in wind-sand coupling field. It is no longer the logarithmic distribution with height. From the Figure 12, it is obvious that along the slope bed surface, the wind horizontal velocity varies greatly below $1 \mathrm{Hs}$ from the bed surface in the pure wind field and shows reverse flow pattern compared with those over the flat bed surface; In general, with wind-sand coupling, the horizontal wind velocity above 2 Hs from the bed surface barely changes. Over the windward slope, the gradient of horizontal velocity gradually increases as it approaches the slope crest and the horizontal velocity was always positive anywhere in the wind flow field; over the leeward slope, there is a reversed flow region and the horizontal velocity is negative between slope surface and $1 \mathrm{Hs}$ in pure wind field.

However, with wind-sand coupling, the horizontal velocity at same height above the bed surface increases as it moves from the position at the windward slope toe to the leeward slope toe. It also can be seen that below $2 \mathrm{Hs}$ from the windward slope surface, the gradient of the horizontal velocity of wind gradually increases as it approaches the slope crest. However, above $2 \mathrm{Hs}$ from the windward slope surface, the gradient increases much greater as it approaches the slope crest. Below $1.5 \mathrm{Hs}$ from the leeward slope surface, the gradient gradually increases as it moves away from the slope top; below $1.5 \mathrm{Hs}$ from the leeward slope surface, the horizontal velocity at that height gradually increases as it moves away from the slope top. Below $1.5 \mathrm{Hs}$ from the bed surface, the horizontal velocity at that height increases as it moves away from the leeward slope toe. As wind moves away from the slope, the variation in velocity decreases with height until the velocity no longer varies with position.

The above results reveal that the impact of saltating sand particles on wind flow is relatively slight over the windward slope, while the slope surface has a great effect on wind flow. Compared with over the windward slope, the impact of saltating sand particles on wind flow is relatively great below 2 Hs over leeward slope. Saltating sand particles have significant influence on wind flow below $2 \mathrm{Hs}$ over leeward slope, especially in the reverse region. As away from the reversed region, the impact of saltating sand particles on wind flow becomes gradually weak.

Figure 13 shows the simulated mass flux profiles over the windward of transverse dune (Hs is $0.1 \mathrm{~m}$ ). It is obvious from the Figure 10 that the vertical change in the mass flux over the slope is different from that over the flat surface, although the mass flux of sand particles still decreases gradually with height over the windward slope.

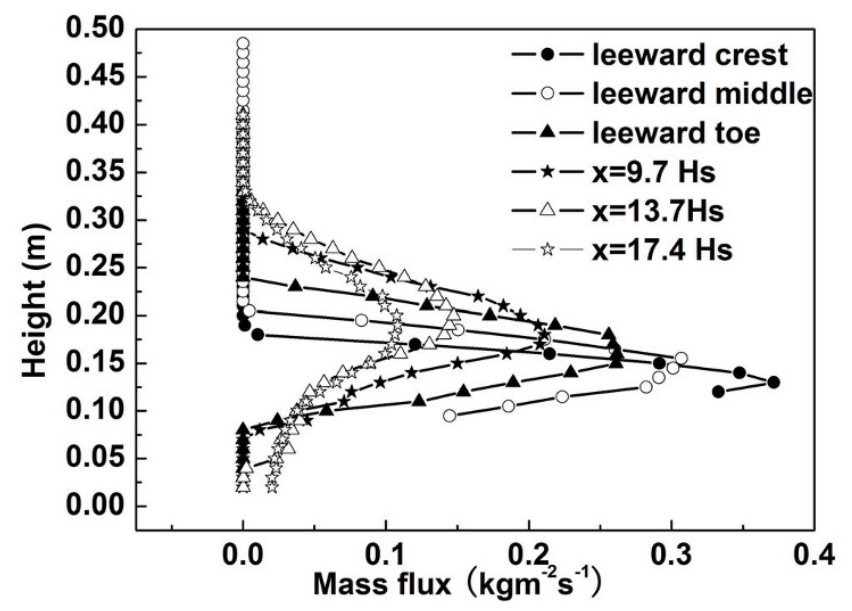

Figure $14 \mid$ Simulated mass flux profiles over leeward of transverse dune.

Figure 14 shows the simulated mass flux profiles over the leeward of transverse dune ( $\mathrm{Hs}$ is $0.1 \mathrm{~m}$ ). Over the leeward slope, the mass flux of sand particles initially increases and then decreases with height. In addition, the maximum mass flux gradually decreases as it moves away from the slope top.

Figure 15 shows the comparison between observed and simulated mass flux profiles behind the leeward of transverse dune (Hs is $0.1 \mathrm{~m})$. It is clear from the Figure 15 that the simulation results of the maximum mass flux are larger than the experiment results, which can be attributed to sand transport on the lee slope of the dune where sand saltation is not dominated as it was on the windward slope. On the lee side, the sand grain avalanche is the dominant sediment transport mechanism which is not characterized by this process ${ }^{17}$. Therefore, in order to accurately simulate aeolian sand transport over the dune, especially on the leeward slope, the only consideration of sand saltation is not sufficient. This study indicates that the simulated maximum mass flux is equal to that obtained from experiment at the position of $6.3 \mathrm{Hs}$ after leeward slope bottom.

In particular, detailed dune models, such as Schwämmle et al. $^{23}$ are computationally too expensive to study a field of transverse dunes, while existing simpler models for dune fields where transverse dunes are treated as interacting particles still lack an accurate modeling of the flow reattachment length ${ }^{40,41}$. Thus these models should be improved by taking into account the important findings of this manuscript' work that this length is affected by the mass flux itself.

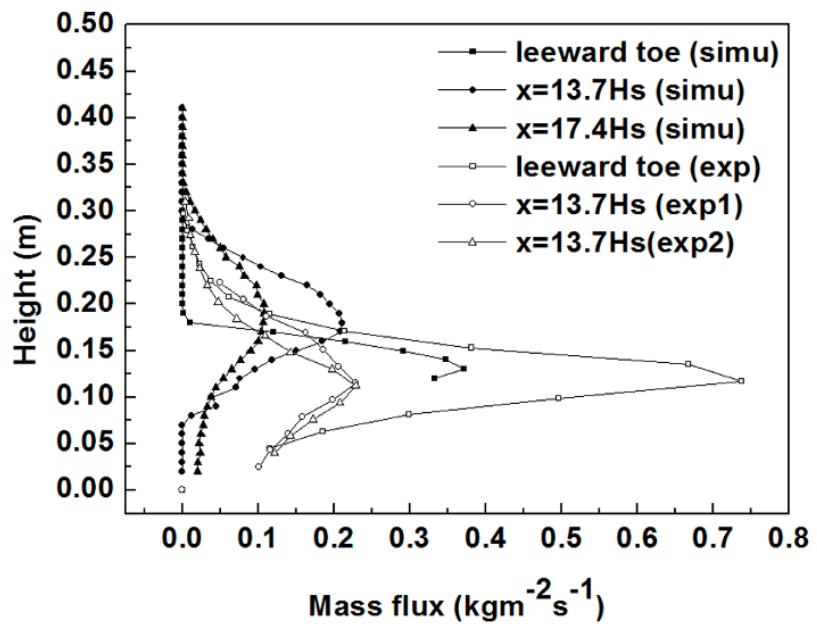

Figure 15 | Observed and simulated mass flux profiles over transverse dune behind leeward slope. 
Table 2 | PDPA system parameters in wind tunnel experiments

\begin{tabular}{lc} 
Parameter & \multicolumn{1}{c}{ value } \\
\hline Focal length of launch lens $/ \mathrm{mm}$ & 500 \\
Laser wavelength/nm & 514.5 (green glow) \\
& 488 (blue glow) \\
Separation distance of laser beam $/ \mathrm{mm}$ & 38.0 (green glow) \\
& 38.0 (blue glow) \\
laser beam diameter $/ \mathrm{mm}$ & 2.220 \\
Interference fringes spacing $/ \mu \mathrm{m}$ & 12.35 (green glow) \\
& 5.86 (blue glow)
\end{tabular}

Therefore, this manuscript is providing valuable information for improving existing simpler models.

This study presents the numerical model for saltating sand particles movement coupling with wind flow over the slope surfaces to simulate windblown sand movement over the windward and leeward slopes, then uses the SIMPLE algorithm to calculate wind flow and simulate sands transport by tracking sand particle trajectories. In addition, the numerical simulation results are compared with the wind tunnel experimental results are conducted in the study. This work starts the numerical simulation of wind-blown sand movement in a complex terrain and is important for studying sand flux in natural environments. It is also helpful to understand the formation process of sand dune.

Our results show that 1 ) over the windward slope, both the velocity gradient of wind and the mass flux of sand particles increase as wind flows up over the slope, while the mass flux decreases gradually with the height increasing; 2) over the leeward slope, both the velocity gradient of wind and the mass flux of sand particles show a trend of first increase then decrease with the height increasing, evidently different from what occurs over the windward slope; 3 ) as away from

\section{Simulation processes}

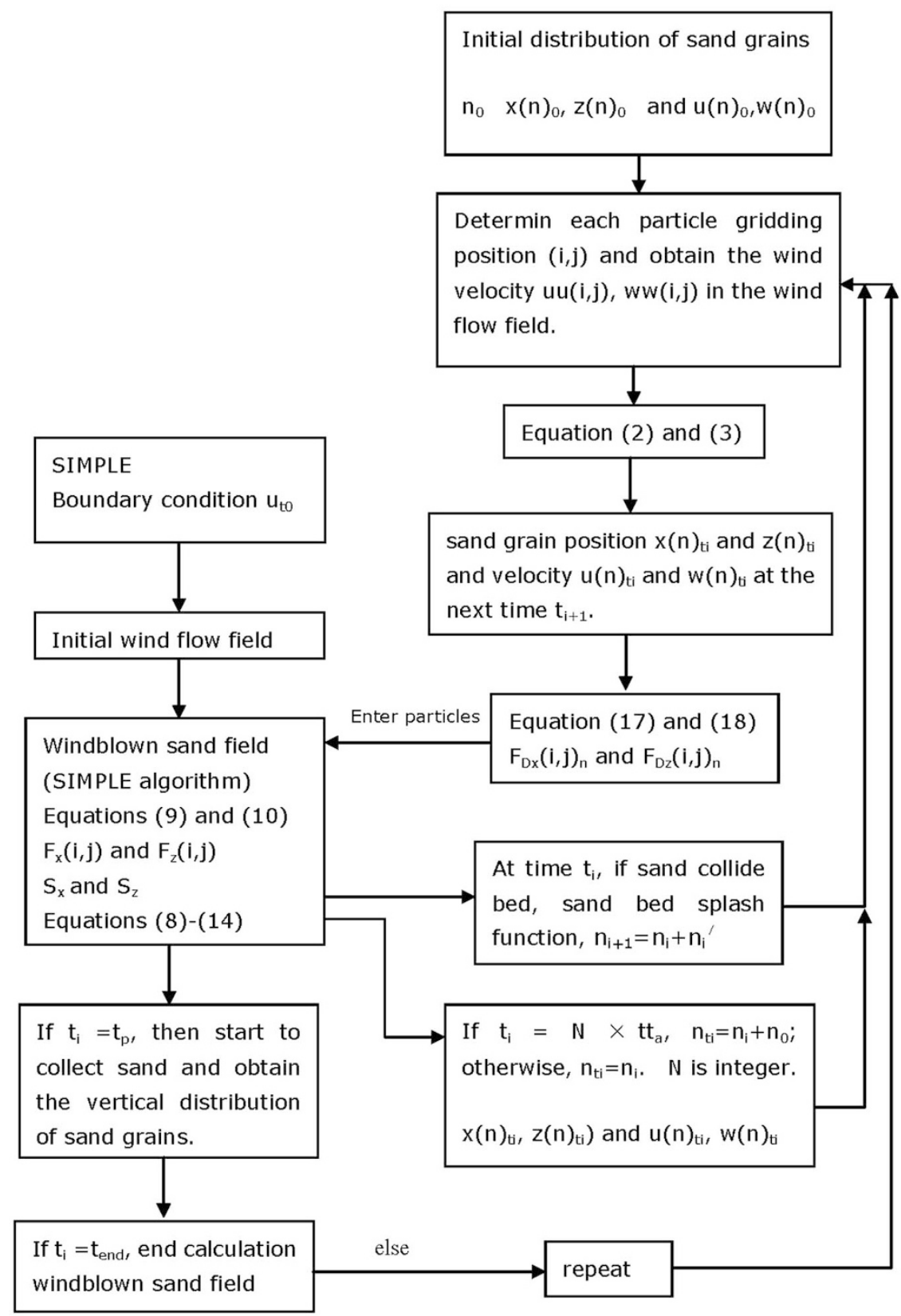

Figure $16 \mid$ Numerical simulation process. 
the crest of the slope, the mass flux reduces from its maximum gradually; 4) a reversed flow region over the leeward slope is present and becomes larger if the wind-sand coupling is considered; 5) the reattachment distance is about 5 times the slope height with no coupling and about 9 times with coupling.

\section{Methods}

Slope landform and wind tunnel experiments. In order to verify the feasibility and accuracy of our numerical simulation model, the pure wind flow velocity was measured over a $0.05 \mathrm{~m}$ high slope by a Phase Doppler Particle Analyzer (PDPA). The wind tunnel experiments over the slope landform were performed in the Key Laboratory of Mechanics on Disaster and Environment, Western China. The experimental section was $20 \mathrm{~m}$ long, $1.3 \mathrm{~m}$ wide and $1.45 \mathrm{~m}$ high.

As a non-contact, real-time measuring system with a fast dynamic response, wide speed range, and high spatial resolution, the PDPA consists of power supply, water cooling system, argon laser, fiber driver, transmitter and receiver units, photomultiplier unit, Doppler signal analyzer, and host computer. Its three-axis coordinate frame system is used to precisely control position measurement. PDPA technique is a kind of optical measurement technique without disturbing the flow field. Compared with ordinary non-contact measurement techniques, PDPA is more sensitive in direction. Laser beam enters the wind tunnel through transparent window on wind tunnel wall. The relationship between the fluid velocity and Doppler frequency shift is:

$$
v=f_{d} \frac{\lambda}{2 n \sin (\theta / 2)}
$$

Where, $f_{d}$ is Doppler frequency shift, $\lambda$ is the laser beam wavelength, $\theta$ is the incident angle, $v$ is the fluid velocity, $\mathrm{n}$ is the fluid refractive index. For air, $\mathrm{n}=1.0002919$. The parameters of PDPA system in wind tunnel experiments are listed in Table 2.

Simulation processes. Wind-blown sands field and sand transport was calculated in our model as in Figure 16.

$\begin{array}{ll}t_{p} & \text { the time that the model starts to collect sands } \\ t_{\text {end }} & \text { the total calculation time is } 3 \mathrm{~s} \\ \mathrm{tt}_{\mathrm{s}} & \text { the time steps of sand movement in the model } \\ \mathrm{tt}_{\mathrm{w}} & \text { the time steps compensating the wind flow field in the model } \\ \mathrm{tt}_{\mathrm{a}} & \text { the time steps that the particles enter the wind flow field in the model } \\ \mathrm{D} & \text { the average particle diameter } \\ \mathrm{n}_{0} & \text { sand grains number at first step } \\ \mathrm{x}(\mathrm{n})_{0}, \mathrm{z}(\mathrm{n})_{0} & \text { the initial position of each sand grain } \mathrm{n} \\ \mathrm{u}(\mathrm{n})_{0}, \mathrm{w}(\mathrm{n})_{0} \quad \text { the initial velocity of each sand grain } \mathrm{n} \\ \mathrm{n}_{\mathrm{ti}} & \text { the sand particles number at the time } \mathrm{t}_{\mathrm{i}} \\ \mathrm{t}_{0}\left(\text { or } \mathrm{t}_{\mathrm{i}}\right) & \text { calculation time } \\ \mathrm{n}_{\mathrm{i}} & \text { rebound and eject particle number } \\ \mathrm{u}_{\mathrm{t}} & \text { the inlet wind velocity profile is fitted from the velocity } \\ \text { profile in the wind tunnel experiment. }\end{array}$

1. Anderson, R. S. \& Haff, P. K. Simulation of eolian saltation. Science. 241, 820-823 (1988).

2. Anderson, R. S. \& Haff, P. K. Wind modification and bed response during saltation of sand in air. Acta Mech. 1, 21-51 (1991).

3. Sørensen, M. \& McEwan, I. On the effect of mid-air collisions on aeolian saltation. Sedimentology. 43, 65-76 (1996).

4. Rasmussen, K. R. \& Mikkelsen, H. E. On the efficiency of vertical array aeolian field traps. Sedimentology. 45, 789-800 (1998).

5. Shao, Y. \& Li, A. Numerical modelling of saltation in the atmospheric surface layer. Boundary Layer Meteorol. 91, 199-225 (1999).

6. Kok, J. F. \& Renno, N. O. A comprehensive numerical model of steady state saltation (COMSALT). J. Geophys. Res. D: Atmos. 114, D17204 (2009).

7. Andreotti, B. A two species model of Aeolian sand transport. J. Fluid Mech. 510, 47-70 (2004).

8. Almeida, M. P., Andrade Jr, J. S. \& Herrmann, H. J. Aeolian transport layer. Phys. Rev. Lett. 96, 018001 (2006).

9. Carneiro, M. V., Pähtz, T. \& Herrmann, H. J. Jump at the onset of saltation. Phys. Rev. Lett. 107, 098001 (2011).

10. Taniere, A., Oesterle, B. \& Monnier, J. C. On the behaviour of solid particles in a horizontal boundary layer with turbulence and saltation effects. Exp. Fluids. 23, 463-471 (1997).

11. Nishimura, K. \& Hunt, J. C. R. Saltation and incipient suspension above a flat particle bed below a turbulent boundary layer. J. Fluid Mech. 417, 77-102 (2000).

12. Lancaster, N., Nickling, W. G., mckenna Neuman, C. K. \& Wyatt, V. E. Sediment flux and airflow on the stoss slope of a barchan dune. Geomorphology. 17, 55-62 (1996).

13. Frank, A. J. \& Kocurek, G. Airflow up the stoss slope of sand dunes: limitations of current understanding. Geomorphology. 17, 47-54 (1996).
14. Wiggs, G. F. S., Livingstone, I. \& Warren, A. The role of streamline curvature in sand dune dynamics: evidence from field and wind tunnel measurements. Geomorphology. 17, 29-46 (1996).

15. Claudin, P., Wiggs, G. F. S. \& Andreotti, B. Field evidence for the upwind velocity shift at the crest of low dunes. Boundary Layer Meteorol. 148, 195-206 (2013).

16. Antoine, F., Claudin, P. \& Andreotti, B. Bedforms in a turbulent stream: formation of ripples by primary linear instability and of dunes by nonlinear pattern coarsening. J. Fluid Mech. 649, 287-328 (2010).

17. Frank, A. J. \& Kocurek, G. Toward a model for airflow on the lee side of aeolian dunes. Sedimentology. 43, 451-458 (1996).

18. Goudie, A., Livingstone, 1. \& Stokes, S. [Recent investigations of airflow and sediment transport over desert dunes] Aeolian Environments, Sediments and Landforms. [15-47] (John Wiley, New York, 1999).

19. Wiggs, G. F. S. Desert dune processes and dynamics. Prog. Phys. Geog. 25, 53-79 (2001).

20. Walker, I. J. \& Nickling, W. G. Dynamics of secondary airflow and sediment transport over and in the lee of transverse dunes. Prog. Phys. Geog. 26, 47-75 (2002).

21. Walker, I. J. \& Nickling, W. G. Simulation and measurement of surface shear stress over isolated and closely spaced transverse dunes in a wind tunnel. Earth Surf. Processes Landforms. 28, 1111-1124 (2003).

22. Parsons, D. R., Wiggs, G. F., Walker, I. J., Ferguson, R. I. \& Garvey, B. G. Numerical modelling of airflow over an idealised transverse dune. Environ. Modell. Softw. 19, 153-162 (2004).

23. Schwämmle, V. \& Herrmann, H. J. A model of barchan dunes including lateral shear stress. Eur. Phys. J. E. 16, 57-65 (2005).

24. Schatz, V. \& Herrmann, H. J. Flow separation in the lee side of transverse dunes: a numerical investigation. Geomorphology. 81, 207-216 (2006).

25. Livingstone, I., Wiggs, G. F. \& Weaver, C. M. Geomorphology of desert sand dunes: a review of recent progress. Earth Sci. Rev. 80, 239-257 (2007).

26. Araújo, A. D., Parteli, E. J., Pöschel, T., Andrade, J. S. \& Herrmann, H. J. Numerical modeling of the wind flow over a transverse dune. Sci. Rep. 3 (2013).

27. Parsons, D. R., Walker, I. J. \& Wiggs, G. F. S. Numerical modelling of flow structures over idealized transverse aeolian dunes of varying geometry. Geomorphology. 59, 149-164 (2004).

28. Herrmann, H. J., Andrade Jr, J. S., Schatz, V., Sauermann, G. \& Parteli, E. J. R. Calculation of the separation streamlines of barchans and transverse dunes. Physica A. 357, 44-49 (2005).

29. Patankar, S. V. \& Spalding, D. B. A calculation procedure for heat, mass and momentum transfer in three-dimensional parabolic flows. Int. J. Heat Mass Transfer. 15, 1787-1806 (1972).

30. Rasmussen, K. R. \& Mikkelsen, H. E. On the efficiency of vertical array aeolian field traps. Sedimentology. 45, 789-800 (1998).

31. Li, Z. S. \& Ni, J. R. Sampling efficiency of vertical array aeolian sand traps. Geomorphology. 52, 243-252 (2003).

32. Willetts, B. B. \& Rice, M. A. Collisions in aeolian saltation. Acta Mech. 63, 255-265 (1986).

33. Beladjine, D., Ammi, M., Oger, L. \& Valance, A. Collision process between an incident bead and a three-dimensional granular packing. Phys. Rev. E: Stat. Nonlinear Soft Matter Phys. 75, 061305 (2007).

34. Oger, L., Ammi, M., Valance, A. \& Beladjine, D. Discrete element method studies of the collision of one rapid sphere on 2D and 3D packings. Eur. Phys. J. E. 17, 467-476 (2005).

35. Werner, B. T. A steady-state model of wind-blown sand transport. J. Geol. 98 , 1-17 (1990).

36. Vinkovic, I., Aguirre, C., Ayrault, M. \& Simoëns, S. Large-eddy simulation of the dispersion of solid particles in a turbulent boundary layer. Boundary Layer Meteorol. 121, 283-311 (2006).

37. Walker, I. J. Secondary airflow and sediment transport in the lee of a reversing dune. Earth Surf. Processes Landforms. 24, 437-448 (1999).

38. Parteli, E. J. R., Schwämmle, V., Herrmann, H. J., Monteiro, L. H. U. \& Maia, L. P. Profile measurement and simulation of a transverse dune field in the Lençóis Maranhenses. Geomorphology. 81, 29-42 (2006).

39. Cooke, R. U., Warren, A. \& Goudie, A. S. Desert geomorphology (UCL Press, London, 1993).

40. Parteli, E. J. R. \& Herrmann, H. J. A simple model for a transverse dune field. Physica A. 327, 554-562 (2003).

41. Diniega, S., Glasner, K. \& Byrne, S. Long-time evolution of models of aeolian sand dune fields: Influence of dune formation and collision. Geomorphology. 121, $55-68(2010)$

\section{Acknowledgments}

This work is supported by the State Key Program of National Natural Science Foundation of China (91325203), the National Natural Science Foundation of China (11172118, 41371034), and the Innovative Research Groups of the National Natural Science Foundation of China (11121202), National Key Technologies R \& D Program of China (2013BAC07B01). 


\section{Author contributions}

H.J. and N.H. designed the research. H.J. implemented the computational model and analysis tools, carried out the simulations and collected the data. H.J., N.H. and Y.Z. wrote the paper. All authors reviewed the manuscript.

\section{Additional information}

Competing financial interests: The authors declare no competing financial interests.

How to cite this article: Jiang, H., Huang, N. \& Zhu, Y. Analysis of Wind-blown Sand Movement over Transverse Dunes. Sci. Rep. 4, 7114; DOI:10.1038/srep07114 (2014).
This work is licensed under a Creative Commons Attribution-NonCommercialShareAlike 4.0 International License. The images or other third party material in this article are included in the article's Creative Commons license, unless indicated otherwise in the credit line; if the material is not included under the Creative Commons license, users will need to obtain permission from the license holder in order to reproduce the material. To view a copy of this license, visit http:// creativecommons.org/licenses/by-nc-sa/4.0/ 